\title{
Narrativas de adolescentes explorados como "mulas" do narcotráfico proveniente da fronteira Brasil-Paraguai
}

\section{Narratives of adolescents exploited as "mules" of drug trafficking from the Brazil-Paraguay border}

Andrea Pires Rocha*

\begin{abstract}
Eles querem um preto com arma pra cima

Num clipe na favela gritando: Cocaína Querem que nossa pele seja a pele do crime (Baco Exu do Blues)
\end{abstract}

Resumo: Sintetiza-se discussões referentes a questão dos mecanismos de controle impetrados pelo racismo, seletividade penal e guerra as drogas, no bojo do Estado penal. Apresenta-se a realidade de adolescentes explorados como mulas na rota de tráfico internacional proveniente da fronteira Brasil - Paraguai. O debate decorre da tese de doutorado “Trajetórias de adolescentes apreendidos como "mulas" do transporte de drogas na região da fronteira (Paraná) Brasil Paraguai: exploração de força de trabalho e criminalização da pobreza. Neste artigo enfoca-se como se davam as viagens, trazendo um pouco das sensações, expectativas, satisfações, medos e riscos que as compunham. Acredita-se que o artigo possibilita algumas aproximações acerca da complexa realidade dos meninos e meninas explorados como "mulas" do tráfico de drogas, demonstrando o quanto estão submetidos a dupla violência, pois, por um lado são explorados pelo narcotráfico, por outro, são criminalizados no bojo da guerra às drogas e, ambos os lados, os colocam em riscos constantes, contribuindo para a composição do juvenicídio.

Palavras-chave: fronteira; tráfico de drogas; mulas; adolescente; juvenicídio.

Abstract: Synthesize discussions regarding the issue of control mechanisms brought about by racism, criminal selectivity and the war on drugs, in the midst of the state penalty. Briefly present discussions regarding the reality of

\footnotetext{
* Docente do Departamento de Serviço Social da UEL. Doutora em Serviço Social pela UNESP, Mestre em Educação pela UEM. Pós-doutora na Escola de Serviço Social da UFRJ.
} 
adolescents exploited as mules on the international trafficking route from the Brazil - Paraguay border. The debate stems from the doctoral thesis "Trajectories of adolescents apprehended as "mules" of drug transport in the border region (Paraná) Brazil - Paraguay: exploitation of the workforce and criminalization of poverty. In this article focus on how the trips took place, bringing a little of the sensations, expectations, satisfactions, fears and risks that made them up. Hope that the article allows a brief approximation about the complex reality of boys and girls exploited as "mules" of drug trafficking, demonstrating how much they are subjected to double contradiction because, on the one hand, they are exploited by drug trafficking, on the other hand, they are criminalized in the midst of war on drugs and, on both sides, put them at constant risk, contributing to the composition of juvenicide.

Keywords: frontier; drug trafficking; mules; teenager; juvenicide.

\section{De onde partimos}

Em uma conjuntura de expansão das vicissitudes do capitalismo, especialmente no contexto da crise econômica agravada pela pandemia do coronavírus e de sua doença COVID-19, observa-se o quanto os caminhos impostos para manutenção da sociabilidade burguesa são perversos para a classe trabalhadora, atingindo de maneira mais direta os "não brancos" ${ }^{1}$ que, via de regra, são os mais pobres no mundo todo. Evidencia-se assim a importância de reflexões acerca do recrudescimento desta lógica no contexto do neoliberalismo que desmonta sistemas de garantia de direitos duramente conquistados, ao mesmo tempo em que sustenta o acúmulo de capital sem rédeas. Em meio desta dinâmica constrói-se mecanismos opressivos e violentos que atingem comunidades inteiras, dentre eles evidencia-se a suposta "guerra às drogas" sobre a qual pretende-se abordar neste texto. Não do ponto de vista mais geral de seus rebatimentos, mas da particularidade que atinge uma parcela dos adolescentes e jovens que, por conta da condição de vulnerabilidade extrema, encontra alguns

\footnotetext{
${ }^{1}$ Utiliza-se essa expressão pois a racialização da sociedade impõe a supremacia branca em todo mundo, portanto, o racismo se expressará de maneira particular em cada país (MUNANGA, 2003). No caso do Brasil, o racismo se volta contra a população negra e indígena.
} 
espaços para venda de sua força de trabalho em atividades ilegais, especialmente contrabando e narcotráfico.

É a partir dessas constatações que amplia-se as reflexões apresentadas na tese de doutorado “Trajetórias de adolescentes apreendidos como 'mulas' do transporte de drogas na região da fronteira (Paraná) Brasil - Paraguai: exploração de força de trabalho e criminalização da pobreza" (ROCHA, 2012). Pesquisa que buscou compreender como se dá a exploração da força de trabalho de adolescentes como 'mulas' do tráfico que decorre da fronteira Brasil Paraguai $^{2}$, a partir da realidade de adolescentes, muitas vezes nomeados neste texto como meninos e meninas, que foram apreendidos transportando drogas proibidas nas rodovias do Paraná em ônibus e automóveis3.

A pesquisa de campo teve como universo os Centros de Socioeducação das regiões oeste e norte do Paraná, situados nos municípios de Foz do Iguaçu, Cascavel, Toledo, Maringá e Londrina e se constituiu em três fases: 1 $^{\mathrm{a}}$.) Em 2009 - 2010 realizou-se pesquisa documental em pastas técnicas dos Centros de Socioeducação dos municípios elencados no universo da pesquisa; $2^{\mathrm{a}}$.) No ano de 2011 deu-se o início da primeira rodada de entrevistas semiestruturadas com adolescentes em internação e em Liberdade Assistida nos mesmos municípios que compõe o universo; $3^{\mathrm{a}}$.) Em 2012 houve a retomada das entrevistas com os mesmos adolescentes já entrevistados em uma perspectiva de analisar a realidade de vida dos mesmos após um ano4.

Destaca-se que na defesa da referida tese, a banca examinadora solicitou que as falas dos adolescentes não fossem publicizadas na íntegra pelo período de

\footnotetext{
2 A construção deste objeto decorreu da experiência de atuação como Assistente Social na execução de medidas socioeducativas em meio aberto em Maringá/PR.

3 Esses adolescentes, por conta do cometimento de ato infracional equiparado a tráfico de entorpecentes foram levados para os Centros de Socioeducação - CENSE, primeiramente na condição de internação provisória e, na maioria das vezes, receberam a aplicação da medida socioeducativa de internação que pode durar até três anos, dependendo da avaliação das equipes das instituições

4 Passou pelo comitê de Ética da UNESP-Franca e também da então Secretaria Estadual da Criança e Juventude do Paraná (SECJ) para autorização das entrevistas, pois algumas delas aconteceram no interior dos Centros de Socioeducação de Foz do Iguaçu, Toledo, Cascavel, Maringá e Londrina (adolescentes B, C, F, G, H, LP), já os adolescentes D e E, no primeiro momento das entrevistas estavam em liberdade e no segundo, estavam em internação por terem cometido homicídio em contexto de disputa de poder do tráfico de drogas. Ressalta-se ainda que as adolescentes AA e IA, estavam em cumprindo medida socioeducativa em meio aberto.
} 
cinco anos preservando a segurança destes sujeitos. Respeitou-se o acordo e passado este período, o artigo em questão apresentará um pouco da realidade estudada a partir da reconstrução de parte da tese que discutiu a questão da fronteira e trouxe subsídios para análise da principal característica da atividade dos adolescentes na condição "mulas": as viagens para o transporte das drogas proibidas. Neste sentido, apresentar-se-á alguns trechos longos de falas dos meninos e meninas, que poderão servir como fontes para outros(as) pesquisadores(as) sobre o tema. Acredita-se, enfim, que as reflexões apresentadas possibilitarão aproximações acerca da complexa realidade dos adolescentes explorados como "mulas" do tráfico de drogas provenientes de uma fronteira.

\section{Racismo, Guerra às Drogas e Juvenicídio}

Para se compreender a questão das drogas e os impactos decorrentes da "guerra às drogas", torna-se essencial a percepção de que é uma guerra contra pessoas, não contra drogas (KARAM, 2012). Além disso, é fundamental levar em consideração de alguns outros elementos de fundo. Primeiro, as substâncias psicoativas, aquelas que alteram o estado físico, mental e emocional, acompanham a história da humanidade, mostrando-se de forma diferenciada em cada momento histórico (ESCOHOTADO, 2004). No bojo dessas reflexões se insere o entendimento de que essas substâncias saíram da esfera do uso ancestral e cultural, tornando-se mercadorias (MARX, 1988) que satisfazem necessidades humanas (CARNEIRO, 2002; ROCHA, 2012).

O segundo ponto mostra-se na compreensão de que como mercadorias a obtenção de lucros se mostra por meio da exploração de mais-valia em seus processos de produção, distribuição, circulação e, quando proibidas possuem moires valores agregados. Tornando-se incontestável a percepção de que é a proibição 5 que inaugura o tráfico de drogas e sua violência, ao levar a gestão das

5 O Proibicionismo tem suas raízes ideológicas no pensamento Puritano que foi uma dissidência do Protestantismo calvinista aderida por ingleses que colonizaram os Estados Unidos da América, que em síntese defendiam a propriedade privada, a acumulação e a exploração, por outro lado, naturalizavam as diferenças sociais e condenavam prazeres, ócio e vadiagem (WEBER, 2004). Esses elementos ideológicos repercutem na esfera política no final do século XIX e ganham corpo 
substâncias proibidas para a esfera obscura da ilegalidade, que se desenvolve sob pilares imensamente violentos (ROCHA, 2012; 2013). A lógica comercial se dá a partir da relação entre sujeitos: fornecedores e consumidores. Relações essas que não são binárias, pois entre os fornecedores estão aqueles que gerenciam e administram o negócio lucrativo das drogas e os que tem a força de trabalho explorada para produção, transporte e venda a varejo. E, como consumidores estão os clientes e também muitos jovens negros e pobres, que por fazerem consumo de drogas proibidas são tratados como traficantes e pegos na implementação da seletividade penal ${ }^{6}$.

Ou seja, embora a ideologia proibicionista proponha uma distinção dicotômica entre usuários e traficantes, estudos comprovam que as legislações delineadas por essa lógica são eficazes instrumentos de controle social e racial, ditando quem deve ser tratado como traficante, submetido ao controle penal, e quem é visto como usuário, digno de tratamento na esfera da saúde. A construção da retórica da "guerra às drogas", na década de 1970, decorre de determinantes internos a realidade dos Estados Unidos da América, os quais, segundo Alexander (2017) se referem ao fim da formalização da segregação racial buscando-se novas estratégias para se manter os negros como inimigos sociais. Mas também se dá em resposta a uma necessidade internacional de superação da crise do capitalismo que se asseverava naquele contexto, culminando na década seguinte na implementação do Estado neoliberal de cunho penal, que segundo Wacquant (2001; 2013) desmonta a proteção social e fortalece as políticas punitivas7.

Portanto, a "guerra às drogas", torna-se a justificativa para o encarceramento em massa de negros e pobres em todos os países que aderem a ideologia proibicionista e implementam o Estado neoliberal. Sabe-se que

por meio em legislações que passam a proibir algumas drogas no início do século XX, primeiro no próprio Estados Unidos, depois expandindo-se para o mundo em decorrência da própria política de Segurança Nacional daquele país (ROCHA, 2012; RODRIGUES, 2003; DELMANTO, 2010 BOITEUX, 2006; VALOIS, 2017; LIMA, 2009) Além disso, é importante frisar que o Proibicionismo foi instrumento de controle utilizado por Ford para potencializar seus esquemas de superexploração (GRAMSCI, 2008)

6 Para estudos acerca do conceito de seletividade penal sugerimos: Baratta (1999) e Zaffaroni (2014). Sobre a seletividade no contexto da questão das drogas: Passetti (1991), Boiteux (2006), Lima (2009), Rocha (2012; 2018), Alexander (2017), Ferrugem (2019), Valois (2017)

7 Giorgi (2013) e Garland (2014), também desenvolvem reflexões importantes sobre o lugar do Sistema Penal na sociedade contemporânea. 
historicamente o Brasil tem importado a política de drogas dos EUA8, as quais se somam ao racismo estrutural entendido como "decorrência da própria estrutura social, ou seja, do modo 'normal' com que se constituem as relações políticas, econômicas, jurídicas e até familiares[...]" (ALMEIDA, 2018, p. 38). Lógica que tem impetrado mecanismos de seletividade penal desde o Código Criminal do Império de 1830, utilizado para a repressão às insurgências negras 9 e como mecanismo de controle penal das primeiras expressões da questão social que se mostravam dos processos de urbanização. Características que se agravam no Código Criminal da República de 1890, este sob a influência do pensamento lombrosiano, criminalizando capoeira e outros elementos sociais e culturais próprios da população negra e levando as consequências da política de exclusão dos negros das relações de trabalho livre, para a administração penalizatória na sociabilidade construída após o fim da escravidão ${ }^{10}$ (FLAUZINA, 2006; GÓES, 2015). O Código Criminal só foi substituído pelo Código Penal da década de 1940, em vigor até os dias atuais, que se vale de construções ideológicas dos negros como suspeitos por "natureza".

Esta lógica não excluí os adolescentes negros e pobres. A primeira legislação foi o Código de Menores de 1929, no qual ainda se consideravam os "capoeiras" como uma categoria delituosa. Desde os anos 1940, a política voltada à infância e juventude foi delineada pelo pensamento higienista e eugênico, determinadas pela questão de raça e classe. Na década de 1960 a implantação da FUNABEM Fundação Nacional de Bem Estar do Menor, recrudesce esse modelo de criminalização, o que ganha corpo no Código de Menores de 1979 (RIZZINI, 2011; FALEIROS, 2011). Após a luta de protagonistas coletivos, a Constituição brasileira de 1988 adere ao princípio da proteção integral e considera crianças e

\footnotetext{
8 Além disso, vale a pena destacarmos que no caso da criminalização da maconha, o Brasil foi pioneiro, antecedendo na década de 1930, até os EUA (LIMA, 2009; SAAD, 2019)

9 Segundo Malaguti Batista (2014) e Moura (2018), a resistência negra a partir da fuga e organização em quilombos já era realidade no país desde o século XV, no entanto ganham novas proporções a partir de insurreições urbanas, as quais também foram influenciadas pela experiência do Haiti, onde ocorre a primeira revolução negra da história no período de 1791 à 1804. Sobre a Revolução do Haiti como prova dos limites impetrados pela concepção burguesa de Direitos Humanos, que tiveram como marco a Revolução Francesa, sugere-se a leitura de Trindade (2011), Losurdo (2006) e James (2010).

10 Soma-se as legislações penais um conjunto de outras leis influenciadas pelo pensamento Eugênico (DIWAN, 2018) que colaboraram para a implementação da política de embranquecimento e do genocídio do negro brasileiro, elementos negados pela implementação do mito da democracia racial (NASCIMENTO, 2016).
} 
adolescentes com pessoas em processo de desenvolvimento. O Estatuto da Criança e do Adolescentes de 1990 define que os adolescentes entre 12 e 18 anos incompletos que cometeram delitos cabem as medidas socioeducativas, os quais não passam ilesos mediante a seletividade penal herdada do racismo e das teorias que o fortalece.

Portanto, a construção dos negros como inimigos, sejam eles adultos ou adolescentes, já cristalizada nas relações sociais brasileiras, ganha novas nuances a partir da "guerra às drogas" e seu agravamento impetrado no bojo do Estado neoliberal de cunho penal. A Lei 11.343 que constitui o SISNAD - Sistema Nacional de Políticas Públicas sobre Drogas (BRASIL, 2006), conhecida como a atual "Lei de Drogas" brasileira, teve na época de sua aprovação grande repercussão, pois abrandou as sanções para os usuários de drogas (tratamento, prestação de serviço comunitário) e tornou mais rígidas as penas direcionadas aos traficantes (reclusão de 5 a 15 anos), mantendo, portanto, a lógica das legislações anteriores assentadas nas cisões determinadas pela ideologia proibicionista. Boiteux (2006) tece problematizações, apontando que depois da implantação desta lei houve um grande crescimento das prisões por tráfico de drogas, especialmente negros e pobres.

Os impactos se materializam na produção do encarceramento em massa e na violência letal decorrente de operações policiais ou de acerto de contas no interior do próprio tráfico de drogas. Elementos que se comprovam na realidade a medida em que o Levantamento Nacional de Informações Penitenciárias (BRASIL, 2020a), aponta que no período de junho a dezembro de 2019, havia 748.009 pessoas privadas de liberdade no país11, destas 66,69\% eram negras, somando-se pretos e pardos, 4,94\% mulheres12. Do total, 44,79\% tinham entre 18 e 29 anos de idade. Em relação aos delitos, 50,96\% foram contra o patrimônio e 20,28\% tráfico de drogas, os quais somados correspondem a 71,24\% dos crimes que culminam na privação de liberdade.

O Levantamento Anual SINASE - Sistema Nacional de Socioeducação (BRASIL, 2019, p. 29) referente aos dados de medidas socioeducativas privativas

\footnotetext{
${ }^{11}$ Destas 48,47\% estavam em regime fechado; $29,75 \%$ em prisões provisórias/preventivas; $17,84 \%$ Semiliberdade; 3,36\% em Ambulatório Prisional; 0,58\% estavam cumprindo Medidas Cautelares. ${ }^{12}$ Não há dados oficiais sobre população LGBTTI+
} 
de liberdade no país, apontam um total de 26.109 adolescentes atendidos, sendo "17.811 em medida de internação (68,2\%), 2.160 em regime de semiliberdade $(8,3 \%)$ e 4.832 em internação provisória $(18,5 \%)$, no período havia também "outros 937 adolescentes/jovens em atendimento inicial (3,6\%), $306 \mathrm{em}$ internação sanção $(1,2 \%)$ e 63 em medida protetiva (o,2\%)”. Os atos infracionais com maiores índices foram: roubo qualificado 4.504; tráfico de drogas 3.601; roubo 3.045; homicídio, 1074; e homicídio qualificado 696. Em relação ao quesito raça/cor o documento apresenta que,

$56 \%$ dos adolescentes e jovens em restrição e privação de liberdade foram considerados pardos/negros, em 2014 eram 61\%; e em 2016 eram 59\%, [...]; 21\% foram atribuídos a cor branca em 2014, 23\% no ano de 2015 e em 2016 22\% que são variavelmente das regiões Sul e Sudeste; menos de $1 \%$ a cor amarela: 2014 - 0,7\%, 2015 - 0,8\%, e 2016 - 0,9\%; a etnia indígena em 2014 e 2015 teve o mesmo índice de 3\% mas em 2016 houve um aumento para 1\%; 22\% dos adolescentes e jovens não tiveram registro quanto a sua cor, sendo classificados na categoria sem informação em 2014, em 2015 foram 15\% e em 2016 foram $17 \%$.

Ou seja, os adolescentes negros, também são a maioria no contexto da execução das medidas socioeducativas de internação, como acontece nos dados do sistema prisional. Já em relação aos homicídios no Brasil, o Atlas da Violência (BRASIL, 2020b), aponta que dos 57.956 homicídios no Brasil ocorridos em 2018, 53,3\%, eram referentes a jovens e 75,7\% a negros, somando-se os pretos e pardos, havendo também a problematização da questão da violência provocada pela disputa de organizações vinculadas ao narcotráfico. Waiselfisz (2017, p. 41) traz como agravante para a questão do alto índice de homicídios com armas de fogo no Brasil a questão dos municípios de fronteira, "que, por sua localização estratégica em áreas de fronteira internacional, são rota de grandes organizações transnacionais de contrabando de produtos ou armas, pirataria e tráfico de drogas".

Neste contexto, os trabalhadores e trabalhadoras que se situam nos elos mais vulneráveis do lucrativo negócio das drogas são atingidos pela seletividade penal, sofrem com a criminalização, perdem a liberdade e, não raras vezes, pagam com a própria vida. Isto posto, concorda-se com pesquisadores, ativistas, juristas, 
entre outros atores, que situam a questão da guerra às drogas na esfera do controle da juventude pobre e negra (FEFFERMAN, 2006; ROCHA, 2012; 2018; FERRUGEM, 2019; D'ELIA FILHO, 2015). A realidade dos adolescentes explorados pelo tráfico de drogas é assim delineada, por isso, também insere-se neste contexto o debate referente ao Juvenicídio cunhado por Valenzuela (2015),

O juvenicídio se inicia com a precarização da vida dos jovens, a ampliação de sua vulnerabilidade econômica e social, o aumento de sua condição de cidadania violada e a diminuição de opções disponíveis para que possam desenvolver projetos viáveis de vida. [...] diversos cenários latino-americanos caracterizados pelo miserável assassinato de pessoas que possuem identidades desacreditadas que se encontram vulneráveis frente as forças do Estado e frente a grupos paramilitares do chamado crime organizado [...] (VALENZUELA, 2015 p. 3 - 4, tradução nossa)

Ou seja, o juvenicídio é compreendido a partir de múltiplas determinações que estão na esfera econômica, social, política e cultural, portanto, a morte, o extermínio dos jovens é a conclusão do processo que se inicia na violação de direitos desde a infância, realidade que atinge em cheio a vida dos meninos e meninas explorados como "mulas" do tráfico de drogas proveniente da fronteira Brasil - Paraguai.

\section{Fronteira Brasil - Paraguai: fluxos legais e ilegais}

A rota de tráfico internacional acontece essencialmente pelas rodovias: BR277 que liga o Porto de Paranaguá à Ponte Internacional da Amizade (Foz do Iguaçu - Ciudad del Est); BR-369, que tem como um dos seus polos a cidade de Cascavel, atravessando todo estado de São Paulo e chegando até parte de Minas Gerais; e a BR-163 que integra o Centro Norte ao Centro Sul e Oeste do país, ligando portanto, o Paraná ao Mato Grosso do Sul, contornando a fronteira Brasil-Paraguai. Além das três rodovias citadas, há a BR-272, que é um projeto de rodovia transversal brasileira, que ligará o estado de São Paulo até Guaíra, no Paraná, divisa com Mato Grosso do Sul e fronteira com Paraguai. Além disso, observou-se que a extensa malha viária composta por inúmeras rodovias vicinais, 
também são utilizadas para o transporte de drogas, pois muitas vezes estão isentas de fiscalização.

A pesquisa mostrou que essa rota de tráfico de drogas que atravessa o estado do Paraná se consolida a partir de determinantes que se entrecruzam: a) o fato de situar-se em uma região de tríplice fronteira, que envolve o Paraguai, potencial fornecedor de maconha para o Brasil; b) por possuir uma extensa malha rodoviária, que foi construída para o escoamento da produção agrícola, ligando a fronteira a portos e aos grandes centros econômicos do País e vice-versa. Essas constatações empíricas, exigiram a busca de reflexões que dessem conta de entender espaço, território e fronteira, como categorias que perpassam as definições de limites nos mapas. Ou seja, fez-se necessária a aproximação de teorizações que auxiliassem a observar as relações objetivas e subjetivas que possibilitam que uma região fronteiriça se construa de forma particular, diferenciando-se de outras regiões. Pois, como ensina Milton Santos,

\begin{abstract}
O espaço reproduz a totalidade social na medida em que essas transformações são determinadas por necessidades sociais, econômicas e políticas. Assim, o espaço reproduz-se, ele mesmo, no interior da totalidade, quando evolui em função do modo de produção e de seus momentos sucessivos. Mas o espaço influencia também a evolução de outras estruturas e, por isso, torna-se um componente fundamental da totalidade social e de seus movimentos. (SANTOS, 1979, p. 18).
\end{abstract}

Se o espaço está inserido em uma totalidade e possibilita a construção de outras estruturas, é basilar que a observação dos espaços ocupados na fronteira entre Brasil-Paraguai se dê a partir da consideração de ausências e presenças. Ausências de políticas sociais, de organizações comunitárias. Presenças de atividades ilegais, do narcotráfico, da exploração, corrupção e abuso policial. Em meio de ausências e presenças, o lugar do Estado se mostra de forma ambígua, pois, à medida que está ausente no que se refere a garantia de direitos humanos e sociais, está presente a partir do controle e da violência institucional, principalmente no que se refere o recrudescimento da criminalização e do encarceramento em massa, voltado essencialmente contra negros e pobres, cuja as bases foram apresentadas na introdução deste texto. 
Em uma perspectiva de situar a ilegalidade presente na fronteira, analisouse este fenômeno a partir de elementos que decorrem das relações estabelecidas pelo modo de produção capitalista, as quais se mostram de forma direta na luta de classes que também se manifesta na divisão social, técnica e racial do trabalho, reconfigurando o território e estabelecendo novas geografias, como nos ensina Santos,

A cada movimento social, possibilitado pelo processo da divisão do trabalho, uma nova geografia se estabelece, seja pela criação de novas formas para atender as novas funções, seja pela alteração funcional das formas já existentes. Daí a estreita relação entre divisão social do trabalho, responsável pelos movimentos da sociedade, e a sua repartição espacial. (SANTOS, 1979, p. 40)

Desta forma, vê-se que o estabelecimento de uma "nova geografia" pode também sofrer influências de atividades ilegais, considerando-se desta forma que dentre as relações territoriais e sociais estabelecidas na fronteira essas atividades também compõem a divisão social e racial do trabalho. Além disso, Machado (2000, p. 1), explica que as fronteiras "pertencem ao domínio dos povos”, ou seja

[...] se for certo que a determinação e defesa dos limites de uma possessão ou de um estado se encontram no domínio da alta política ou da alta diplomacia, as fronteiras pertencem ao domínio dos povos. Enquanto o limite jurídico do território é uma abstração, gerada e sustentada pela ação institucional no sentido de controle efetivo do estado territorial, portanto, um instrumento de separação entre unidades políticas soberanas, a fronteira é lugar de comunicação e troca. Os povos podem se expandir para além do limite jurídico do estado, desafiar a lei territorial de cada estado limítrofe e às vezes criar uma situação de fato, potencialmente conflituosa, obrigando a revisão dos acordos diplomáticos.

Desta forma compreende-se um pouco da dinâmica existente na fronteira entre Argentina - Brasil - Paraguai, priorizando a relação entre os dois últimos. Como bem expressa a autora acima, a fronteira deve ser vista como território que perpassa os limites espaciais e as determinações jurídicas, pois é "o sistema produtivo de fronteira que combina comportamentos legais com ilegais [....]" 
(MACHADO, 2005, p. 268). Ao se remeter a fronteira entre Foz do Iguaçu e Ciudade Del Este, explica que:

No campo financeiro, a cidade paraguaia abriga mais de uma dezena de bancos paraguaios e estrangeiros utilizados por nacionais brasileiros e argentinos não só para transações legítimas como também para operações de evasão fiscal e lavagem de dinheiro. [...]. (MACHADO, 2005, p. 268)

Ressalta-se ainda que o contexto dos fluxos de bens, capitais e pessoas devem, segundo a autora, ser tratados a partir da "noção de zona de fronteira", caracterizada por interações internacionais que "criam um meio geográfico próprio de fronteira, só perceptível na escala local/regional”. Isto posto, é indiscutível que o contrabando e o narcotráfico compõem de maneira bem particular a paisagem da fronteira Brasil-Paraguai. Neste cenário, torna-se evidente que uma parcela da população em situação de pobreza, desemprego e submetida a extrema violação de direitos, especialmente pessoas que residem às margens do Rio Paraná, a prestação de serviços para as atividades ilícitas compõe o cotidiano de forma direta ou indireta.

Os fluxos ilegais acontecem a partir da utilização de pequenas embarcações que atravessam o rio ou, na maioria das vezes, por meio do trânsito a pé na Ponte Internacional da Amizade. Em relação a realidade dos adolescentes que são explorados como "mulas" no transporte de drogas, muitos foram apreendidos na própria ponte/rio e na rodoviária de Foz do Iguaçu, mas, a grande maioria foi apreendida em ônibus que saíram da região de fronteira rumo aos mais diferentes destinos do país. Na primeira fase da pesquisa de campo, que teve como fonte documental as pastas técnicas dos Centros de Socioeducação, levantou-se um total de 53 adolescentes que foram internados provisoriamente por terem sido apreendidos transportando drogas proibidas,

26 adolescentes residem na fronteira ou região de fronteira (sendo eles do estado do Paraná, Mato Grosso do Sul ou Paraguai), portanto retiraram a droga na própria região de moradia e 27 adolescentes saíram de suas cidades ou regiões para buscar a droga na fronteira ou região de fronteira (sendo eles de outras regiões do Paraná e de outros estados da federação). Este dado nos revela que na situação específica de nossa amostra, quase a metade dos adolescentes foi contratada para levar drogas 
para outras cidades e regiões e a outra metade foi contratada para ir buscar drogas na fronteira. (ROCHA, 2012, p. 240 - 241)

As informações levantadas revelaram que não só adolescentes residentes na fronteira ou na região trabalham no transporte de drogas, mas muitos são contratados em outras regiões e se direcionam até a região para buscá-las, traduzindo que a função de "mulas" do tráfico pode empregar meninos e meninas de qualquer região do país. No entanto, na pesquisa qualitativa que aconteceu por meio de entrevistas com adolescentes em cumprimento de medida socioeducativa privativa de liberdade ou em meio aberto, esses majoritariamente eram do Paraná, com exceção dos adolescentes paraguaios, como será apresentado na sequência.

\section{4 “Pé na estrada" e viagens: narrativas dos adolescentes}

Viagem é: “1. O ato de transportar-se de um ponto a outro distante. 2. Navegação, travessia. 3. Percurso. 4. Relação escrita dos acontecimentos ocorridos numa viagem e das impressões que ela causou. 5. [Informal] Estado alucinatório provocado pelo consumo de certas drogas”. Dentre as explicações apresentados no dicionário virtual, o primeiro e o último se vinculam quando se fala da realidade dos "mulas" do tráfico de drogas, pois as viagens acontecem para proporcionar "viagens" alucinatórias. Para apreensão das características desta função no interior do narcotráfico, dialogou-se com dezessete adolescentes, os quais, durante as entrevistas demonstraram que a vivência delineada pelo trabalho no tráfico de drogas, que é composto por momentos de satisfações e riscos.

Em linhas gerais observou-se que mesmo possuindo histórias singulares, há particularidades que se materializam a partir de um cotidiano constituído por extrema situação de exclusão social, política e econômica. Este artigo apresenta os depoimentos de duas meninas (IA residente na região de fronteira e AA residente há mais de $400 \mathrm{~km}$ da fronteira), sete meninos (B, C, F, G, H, residentes 
na região de fronteira; $\mathrm{D}$ e E residentes há mais de $400 \mathrm{~km}$ da fronteira) e de $\mathrm{LP}^{13}$, adolescente paraguaio apreendido na região de fronteira. As narrativas foram transcritas sem correção do português, em uma perspectiva de se manter coloquialidade e gírias, considerando que os signos linguísticos também têm muito a dizer, como nos ensina Bakhtin.

\subsection{Viajar é bom!}

Os diálogos com os adolescentes surpreendem à medida que demonstram o quanto "viajar é bom”. As narrativas enfatizam as experiências vivenciadas durante as viagens, especialmente por conheceram pessoas e lugares, vivenciarem momentos "ímpares", deparando-se com o desconhecido, o que para eles apresentase como algo bem sedutor. Frases como "eu nunca tinha ido à praia", foram bem recorrentes, por isso, inicia-se a elucidação dos relatos empíricos demonstrando os depoimentos a respeito das viagens propriamente ditas e das sensações que tiveram, um exemplo,

Roubar, tipo, você passa mais risco né. Traficar não. Traficar você joga o baguio ali no busão e se joga. Ai você pode conhecer várias cidades, onde você for. Vai depender de sua caminhada. [...] muitos lugares no Brasil. [...] É já fui pra São Paulo, Balneário de Camboriú. Santa Catarina eu conheço quase todas cidades. (Adolescente F)

O depoimento tece comparações entre os delitos roubo e tráfico de drogas, pois segundo o adolescente roubar é mais arriscado por envolver armas e violência de maneira mais direta. Já a questão do transporte de drogas acontece, segundo ele, de forma tranquila e ainda possibilita novas vivências. A maioria dos adolescentes apresentou falas neste sentido, abordando o prazer das viagens, o fato de ficarem em hotel, de irem para praia, conhecerem lugares e pessoas. Como narra B: "vai, às vezes paga um hotel lá, daí já deixa reservado, você tem que ir naquele hotel. Daí vai tudo no cartão deles” e F: “aí você já pega seu dinheiro e

13 Os adolescentes do sexo masculino serão identificados com letras maiúsculas, quando paraguaios se acrescenta a letra P. Quando do sexo feminino terão uma letra maiúscula acompanhada da letra A 
embarca no busão. Eles compra a passagem pra você voltar. Não tem despesa de nada”. A experiência relatada por $\mathrm{G}$ também é apresenta alguns elementos a serem destacados,

\begin{abstract}
Ah, foi massa [risos]. Parecia que não tinha nada, porque foi uma mulher junto comigo [no ônibus]. Só que, ela, tipo, ela só foi junto comigo só pra mostrar a casa, o lugar. Mas dentro do ônibus ela não tinha nada a ver comigo, se desse alguma coisa comigo [...]. Dormi na casa da mulher [...]. Ela tinha os pais dela, falou que tinha trombado eu na rua. Que tinha trombado eu na rodoviária. Que eu não sabia onde meus pais morava. Jogando ideia nos pais dela. [risos] (Adolescente G)
\end{abstract}

Ele dormiu na casa da mulher que contratou a entrega da droga, contou com muito gosto a experiência, referiu que foi muito bem tratado pela família da pessoa. Essa experiência evidencia que os pequenos distribuidores de drogas se utilizam destes adolescentes como escudos protetivos em caso de alguma abordagem policial. Outro elemento recorrente foi o fato de permanecerem na casa dos contratantes, pois muitas vezes os adolescentes vão buscar drogas na fronteira e dependem de vários elementos para retornarem. Como nos contou IA, chegou a permanecer um mês no Paraguai e neste período passeou bastante e fez muito uso de drogas,

[...] Nossa, eu usei muita droga, porque lá. [...] Porque é assim, quando a gente sai daqui, tipo, a gente vai buscar droga, a gente encontra alguém lá já, que já tá esperando a gente, entendeu? Já espera a gente na rodoviária, ou já tem um endereço que a gente pega um taxi e vai direto. Ai quando a gente chega lá já faz amizade, bom eu sempre fazia amizade com todo mundo. Já faz amizade com um monte de gente lá. Eles me levava para sair, levava pra conhecer a Bolívia, Foz do Iguaçu, passeava muito na noite. Nossa, eu saia muito de noite. [...] Fiquei [na casa] de [pessoas] paraguaias. (adolescente IA)

A adolescente IA relata com entusiasmo sua experiência no Paraguai, auxiliando na desconstrução do entendimento dicotômico sobre usuários $\mathrm{x}$ traficantes, pois na maioria dos casos os adolescentes fazem uso das substâncias, alguns deles, inclusive, submeteram-se ao trabalho no tráfico para sustentarem o próprio uso. Porém, como tem-se refletido neste texto, a diferença de quem será tratado como traficante ou usuário nada tem a ver com o grau do uso, mas sim 
com os determinantes da questão racial e de classe. No caso da adolescente IA, suas falas sempre demonstraram um cotidiano envolto em riscos, apontando no decorrer da entrevista que muitas vezes foi necessário que ficasse no local pois a viagem depende dos acertos dos grupos contratantes, apontando que "às vezes tem problema na fronteira, daí tem que ficar esperando. Vai da pessoa, vai de como tá lá também, porque eles têm como saber se vai fechar a fronteira de polícia, aí já não podia ir né? Tinha que esperar" (IA). Ou seja, os elementos que definem a construção da viagem também sofrem determinações de informantes externos vinculados ao esquema do narcotráfico. D e E, relataram que chegaram a permanecer duas semanas em Ponta Porã/MS e explicaram que muitas vezes era necessário esperar que chovesse para que as rodovias estivessem livres das barreiras policiais. Essas informações explicam um pouco do esquema do tráfico de drogas a partir do trabalho de "mulas", mas também mostra o quanto o fato de permanecerem em local diferente pode ser interessante para os adolescentes,

[...] [ficaram] duas semanas [...] pra esperar chover né? E: é, monta no ônibus e passa pela barreira da polícia na chuva [...] Só se tiver denúncia vai parar, se não tiver não para ninguém. [...] D: na casa do contato. [...] E: comendo, esperando dá a hora de vir embora. [...] (adolescentes D e E)

As narrativas comprovam que o fato desses adolescentes pertencerem a grupos submetidos as piores expressões da questão social, dentre elas a pobreza e o cotidiano em territórios escassos de políticas garantidoras de direitos sociais e ocupados por políticas de controle e repressão, fez com que as vivências como "mulas" trouxessem nuances de momentos prazerosos. Outro aspecto entendido por estes adolescentes como positivo se mostrou na remuneração financeira. Alguns depoimentos demonstram que para a maioria dos adolescentes os medos e riscos são superados em nome dos ganhos materializados no valor que seria pago pela viagem. A exemplo do relato abaixo:

Tinha medo, ao mesmo tempo falava assim: fiz muitos planos. Fiz muitos planos pro dinheiro que ia receber, [...] Meu medo maior assim era de pegar assim, de acontecer alguma coisa, não só da polícia pegar nós, mas de acontecer alguma coisa mais. Porque, assim, a gente sabe o que tava levando, sabia que a gente tava correndo muito risco. E nós tava com muito medo. A viagem inteira 
nós ficou passando mal. Porque eu nunca tinha levado. (adolescente AA)

Fica claro que na percepção da adolescente, valeria a pena se submeter aos riscos, considerando que poderia realizar seus planos, os quais, na totalidade do relato se referiam a satisfação de desejos de consumo, como comprar de roupas e sapatos. Outro depoimento na mesma linha,

Você sempre fica pensando né?!. No começo você fica sabendo o valor que vai ganhar né?! Ai você fica pensando o que vai fazer com aquele dinheiro, tipo vou fazer isso, vou conseguir isso, vou fazer aquilo, vou ajudar e tudo. Vou comprar, vou me $\operatorname{armar}^{14}$. Você fica pensando essas coisas, vem na sua cabeça assim. Você vai pensando, mas uma hora você chega, você consegue, depois que tá com dinheiro, até uma alegria traz em você. [...]. (adolescente C)

O fato do adolescente referir que pretendia se armar, refere-se muito ao poder que as armas de fogo impetram àqueles colocados socialmente em contexto de exclusões de diferentes níveis, como Zaluar (1996) tem tecido reflexões desde a década de 1990. Essa questão das armas também traduz o risco eminente entre matar e morrer que esses adolescentes são colocados. Além disso, a narrativa torna perceptível como a construção de valores delineados pelo fetiche da mercadoria e a construção de desejos de consumo compõem essa realidade. Além disso, as narrativas evidenciam o quanto falta a esses adolescentes possibilidades concretas para a construção de projetos de vida prometidos pela sociedade meritocrática. O conjunto de relatos demonstraram que esses meninos e meninas se veem assolados em limites que os impossibilita de acreditar na possibilidade da construção de vivencias longe do tráfico de drogas. Alguns deles chegaram a problematizar que o valor que recebiam em uma viagem era o mesmo que seus familiares receberiam em um mês de trabalho, por isso valeria a pena enfrentar os riscos que envolviam o emprego no tráfico de drogas. A fala a seguir relaciona muito os sentimentos ambíguos durante a viagem,

14 Pouquíssimas vezes houve menção a questão da compra de armas. A maioria absoluta dos adolescentes viajam desarmados. Talvez o adolescente em questão também estaria vinculado a algum ponto de venda a varejo. 
Olha, eu não sentia nada, eu queria que acabasse logo pra mim pegar o dinheiro. Só isso. Tipo assim, hoje assim eu me arrependo, mas antes assim, eu queria muito dinheiro, porque essa vida é uma vida fácil, porque praticamente você não tem que fazer nada. Você só tem que andar de ônibus e voltar. Quando eu ia assim, pra lá, eu curtia muito, festava muito sabe? Então eu gostava muito de ir. (adolescente IA)

A adolescente contemporiza dizendo que se arrependia, mas enfatiza que gostava muito da atividade, pois para ela não se tem que fazer "praticamente nada" e, além disso, ela se divertia nas viagens. Diante dos depoimentos verificouse que, de fato, a possibilidade de serem remunerados financeiramente para realizarem viagens e viverem novas experiências é elemento totalmente relevante, $o$ que não retira os riscos do trabalho, pois os mesmos adolescentes que mencionam esses aspectos, também falaram dos medos que sentiam, como veremos no próximo item.

\subsection{Medos e Intempéries}

Considerando as contradições das atividades prestadas para o tráfico de drogas, ao mesmo tempo em que os depoimentos traziam elementos positivos como apresentados acima, os mesmos adolescentes, abordavam, por outro lado, as angústias e medos durante as viagens. Os relatos, deste modo, transitavam entre os extremos das satisfações e dos riscos, como demonstra as incertezas acompanhavam um dos adolescentes:

Da agonia e não é muito bom, não. Depois que chega no destino certo, ai dá uma aliviada. Mas, você fica no ônibus, fica tipo assim, numa incerteza, vai sempre pensando que vai dar certo, ai você chega você já viu que deu certo [E quando não dá certo?] Aí só lamento. (adolescente C)

O "lamento" era a realidade desses adolescentes, pois todos e todas haviam sido pegos e estavam em privação ou restrição de liberdade, infere-se, portanto, que o fato de estarem em internação talvez evidenciasse para os mesmos o valor da liberdade. A tensão da viagem de ida também foi relatada pelo adolescente LP, que fala que o sentimento durante as viagens é "um pouco forte, pensar que vai 
passar. Quando chegar, alegria grande né?! Mas quando sobe a polícia, dá aquele desespero, mas você consegue controlar o desespero né?!”. As incertezas se mostraram muito mais no que se refere ao fato do risco de serem pegos pela polícia, ou seja, o principal valor humano que está em jogo é a liberdade, "ah, vai de boa, só se a polícia parasse mesmo? [...] ah você sente né, quando vai chegando perto da polícia. [...] o coração começa a disparar né, mas fazer o que? Tem que ir" (adolescente D). Evidencia-se que o "coração dispara" em decorrência do medo e este foi uma sensação que apareceu em quase todas as entrevistas.

A fala de B coloca, inclusive, que dá medo nas primeiras viagens e que depois esta sensação passa, nas palavras dele, “[...] Primeira vez dá medo. [...] Medo de cair preso. E na segunda vez você vai que vai. Se você tentar a sorte, uma hora cai né?”. Como neste depoimento,

A primeira vez dá medo. E depois, você vai umas 5,6 vezes aí tipo, você já vê que tá fácil. [...] Ah, medo da polícia pegar você, ficar trancafiado num lugar desse, [...]. Igual eu mesmo, vou ficar de 6 [meses] a 3 [anos], é a metade da minha vida vou passar aqui dentro. (adolescente F)

Para a fase da adolescência, chegar a permanecer até três anos privado de liberdade ocupa de fato grande parte da vida ${ }^{15}$, internações essas que decorrem muito mais de elementos estruturais os quais permitem que no rol de opções, o trabalho no tráfico de drogas seja considerado como uma boa alternativa para obtenção de remuneração. No entanto, é importante apresentar que mesmo sendo exceção, alguns adolescentes apresentavam desenvolver tarefas mais complexas no tráfico internacional. No caso do adolescente $\mathrm{H}$, que atuava dirigindo uma Van na Ponte Internacional da Amizade com muitos quilos de maconha, chegou a apresentar medo da morte "Tem que arriscar né? A gente vai no risco né [silêncio]. Eu nem sei como é que é [silêncio].[...] Ah sente tudo, medo, adrenalina. Só quando chega mesmo, pra sair do medo" (Adolescente H). Já a menina (IA), que

${ }_{15}$ Cabe ilustrar que em pesquisa posterior, que teve como sujeitos jovens maiores de idade presos por tráfico de drogas, foram unanimes os relatos de que não sabiam o que é ser jovem ou viver a juventude, pois desde a adolescência tinham sido privados de liberdade em internações e prisões intermitentes (ROCHA, 2018). 
se deslocava de uma cidade de médio porte para fronteira, às vezes de ônibus, outras de carro, fez a comparação:

Medo, muito medo. Muito medo, [...]Na fronteira. Lá o menino já falava, abaixa que eles vão dá tiro. E eles davam um monte de tiro. A gente corre um perigo muito grande mesmo, lá eu tinha muito medo de ir pra lá quando eu fazia corre pra lá. Só não tinha medo quando eu ia de ônibus e voltava de ônibus. Ah, quando eu ia de carro eu tinha muito medo. [...] de ônibus não dá medo, porque assim, aqui eu pegava um ônibus que ia direito pra Guaíra, então eu não descia do ônibus, às vezes pra voltar também era a mesma coisa, só não tinha tanto medo. Porque assim, eu sabia que se eu fosse presa no ônibus eu só ia ser presa, entendeu? Agora se fosse pega no carro, tinha o perigo deles levar pro meio de rio e matar. Vixe, Porque lá eles levam mesmo, eu sei que lá eles levam mesmo, lá eles levam pro rio, eles matam mesmo. Às vezes você nem corre deles, eles chegam atirando pra matar. (adolescente IA)

Constatou-se então que no caso dos "mulas" que transportam poucas quantidades em ônibus, o medo é de serem apreendidos e perderem a liberdade. Entretanto, pode-se observar a partir das falas, que o policiamento na fronteira propriamente dita é mais ostensivo e mostra-se de maneira mais agressiva, colocando a vida dos adolescentes em risco extremo. Outro risco relatado, não tanto sobre as viagens em si, mas sim ao trabalho no tráfico de drogas, se mostrou na violência que rege as relações do mercado ilícito,

[O traficante também mata por algum motivo?] Mata. Mata, claro que mata. Mata, sempre ele mata, todo dia ele mata. Traficante que, tipo assim, você não pode dar nenhum mio, cê entendeu? Nossa, é muita coisa, quando você entra nessa vida, tem que já saber muita coisa pra entrar nessa vida, porque você corre o risco dos dois lados, entendeu? Do traficante, porque você nunca pode tentar enganar o traficante, meu. Tem muita gente, colega meu que já morreu, mesmo, daqui de [...] mesmo, que morreu por tentar, querer tentar enganar os traficantes. Mas não compensa, você acaba se enroscando e morrendo por causa de dinheiro, coisa que não adianta, não vale a pena. (adolescente IA)

O depoimento acima foi o mais emblemático no que se refere a questão da violência do narcotráfico. Sendo assim, pode-se afirmar que os adolescentes trabalhadores do tráfico de drogas estão em risco constante, pois se por um lado, as regras do narcotráfico são rigorosas, por outro, as regras da "guerra às drogas" que delineiam a violência estatal também o são. 


\section{3 "Mulas" ou "Iscas"?}

Desde que se iniciou a pesquisa documental prévia, algumas apreensões por denúncias soaram muito estranhas por conta da gama de detalhes que apresentavam, as quais, pode-se supor que só poderiam ter sido feitas por pessoas muito próximas dos "mulas" ou por quem os contratou. Nas entrevistas alguns adolescentes disseram que foram apreendidos em decorrência de denúncias detalhadas, abrindo espaço para questionamentos mais direitos, "[Acontece caso dos próprios contatos denunciarem? Vocês já ouviram falar disso]. D: lógico que já. [...] E: ué ele denuncia a polícia para você e passa uma carreta com tonelada de droga" (Adolescentes D e E). Já no caso de AA, além dela desconfiar que foi o contratante quem denunciou, o policial lhe afirmou,

O policial falou pra mim que os próprio mandante que ligaram falando da cor da blusinha, porque eu acho que eles queriam uma mercadoria mais pesada. Nós levemo dois quilo só [...] 2 quilo de cocaína só, aí eu acho que eles queria levar mais pesada [...] Cor da blusa, cabelo solto. Eles sabia tudo. Eles só tava esperando nós lá mesmo. [...] O policial me afirmou que foi ele mesmo, que foi os próprio mandantes, que nós era laranjinha. Que nós foi mesmo pra cair. (Adolescente AA)

A vivência de IA possibilitou que explicasse melhor o funcionamento deste esquema. O mais curioso é que o tema foi abordado pela adolescente quando foi perguntado se enxergava o narcotráfico como “crime organizado”, vejamos:

Assim, oh.. Eles...Eles meu, eles são assim, muitas das vezes eles usam o menor, tipo assim, ele me manda buscar 30 quilos de maconha numa bolsa, numa mala, pra passar 200 quilos de carro. Na hora que o ônibus tiver parado e eles tiver apreendido, tem uma pessoa dentro do ônibus que liga pros 200 quilos passar. Entendeu? Eles põe o menor pra cair com 30 quilos de maconha lá, porque na hora que tá sendo apreendido ali é mais fácil você passar de carro. (Adolescente IA)

Diante da informação que a adolescente levantou, questionou-se se já havia acontecido com ela, então disse que sim e que não foi informada que havia sido contratada para ser apreendida: “[...] eu fui presa uma vez só assim, pra outras pessoas passar com droga.” (Adolescente IA). O adolescente paraguaio LP 
explica, "a maioria é laranjeira, né. A maioria é pra vim cair, pra passar carreta e todo mundo tá ciente disso. Mas todo mundo cobra por ser preso também", ou seja, há também um valor quando a prisão é combinada. Ao se questionar IA se é normal a utilização de adolescentes como iscas para o desenvolvimento do transporte ela disse:

É normal. Um monte de gente faz isso. No Paraguai, a maioria das vezes eles tão trazendo assim mesmo. Porque eles põe ali 30, 40 quilos, porque eles não põe uma carga muito pequena, tem que por uma carga meio grande, assim, uns 40 quilos pra chamar a atenção da polícia, daí elas vem pra procurar mais e é nesse meio que o carro vai passando, porque eles para todo mundo, todo carro que passa lá eles para, só que...[...] É, quando acontece uma situação assim, aí já dá pra passar. O carro dá pra passar, sempre eles passam com camionete lotada, nossa, muitos quilos. ... muitas vezes já aconteceu de eu tá passando no carro e o ônibus tá parado lá porque foi preso. (Adolescente LP)

A fala dela ajuda a compreender que quando o adolescente é contratado para, de fato, transportar drogas de um local para outro, está compondo um esquema para pequenos traficantes de drogas, os quais mantém a venda a varejo com cargas entregues de forma paulatina (média de 25 quilos de maconha por viagem de adolescente). Já, traficantes médios e grandes, optam pela contratação de adolescentes que servirão como "iscas", o que leva a supor que dentro da logística e do alcance de recursos para a corrupção dos aparelhos de segurança, o esquema das "iscas" é mais barato e funcional.

\section{Desafios postos: é preciso resistir!}

Fronteira é território de contradições e fluxos, isto posto, faz-se importante considerar que a presença de atividades ilegais, contrabando e narcotráfico, na fronteira Brasil - Paraguai constituí sua paisagem e demarca o cotidiano de diferentes formas. A medida que entende-se as drogas proibidas (ou não) como mercadorias, visualiza-se que o mercado ilegal estabelece uma rede que dá conta de processos de produção, distribuição e circulação, compondo, desta forma, a divisão social, técnica e racial do trabalho. Além do mais, a política proibicionista só faz agregar valor a essas substâncias. 
Observou-se, portanto, que a presença do mercado das drogas traz para o território fronteiriço algumas particularidades, dentre eles elenca-se: 1) emprego de força de trabalho nos processos de produção, distribuição e circulação das drogas proibidas; 2) ocupação de grupos criminosos que engendram suas regras a partir da violência; 3) recrudescimento das forças de segurança que, em nome da guerra às drogas, perpetua opressão e violência sobre os pobres, especialmente àqueles que estão nos elos mais frágeis das cadeias do narcotráfico. Estes pontos demonstram que a guerra às drogas se mostra inócua para o que se diz, pois as mercadorias proibidas continuam circulando, e efetiva no objetivo que está em sua essência: o controle da juventude pobre e negra.

O estudo sobre a exploração da força de trabalho de adolescentes como "mulas" comprova que o fluxo do tráfico de drogas internacional se torna "possibilidade" de emprego para adolescentes residentes na própria fronteira, como também para aqueles que residem distante e se direcionam até Foz do Iguaçu e/ou Guaíra para buscar as drogas proibidas. Adolescentes estes, que sofrem com o agravamento das vicissitudes próprias da socialidade capitalista mencionadas nas primeiras linhas deste artigo.

Por sua vez, as narrativas dos meninos e meninas demonstram que o trabalho para o tráfico de drogas é repleto de contradições. Não podendo-se deixar de considerar que a remuneração, maior que da grande maioria dos trabalhos formais ou informais, somadas a questão das viagens e dos atrativos que as acompanham, fazem com que a atuação dos "mulas" entre em uma esfera particular de satisfações. Mas também vem acompanhada de incertezas, medos e riscos, pois a perda da liberdade assombra a realidade dos adolescentes que estão envolvidos com o tráfico de drogas e, pior que isso, o medo da morte, é elemento que compõe o cotidiano repleto de violações e violências. Todos os depoimentos comprovaram a imensa gama de violações de direitos que esses adolescentes estão submetidos e, infelizmente, do período de 2011, início das entrevistas e 2012, finalização da tese, alguns sujeitos já haviam falecido em decorrência da violência letal.

Em síntese constata-se que o juvenicídio brasileiro é determinado pelo racismo estrutural, que tem nas relações contemporâneas a "guerra às drogas" como principal justificativa para efetivar prisões e mortes (ROCHA, 2018). 
Processos que anulam e aniquilam a vida de jovens, especialmente daqueles que estão em condição de vulnerabilidade extrema, pois por um lado são explorados pelo narcotráfico e por outro sofrem com as pressões das forças de segurança pública, os quais tem a vida colocada em risco pelos dois lados. E quando não morrem, são acometidos por uma vida privada de liberdade. Realidade perversa que pede a urgência do fortalecimento de resistências antirracistas, antipatriarcais, anticapitalistas e antiproibicionistas, uma intersecção de lutas, como convida Angela Davis (2018).

\section{REFERÊNCIAS}

ALEXANDER, Michelle. A nova segregação: racismo e encarceramento em massa. Tradução de Pedro Davoglio. São Paulo: Boitempo, 2017.

ALMEIDA, Silvio. O que é racismo estrutural? Belo Horizonte: Letramento; Justificando, 2018. (Série Feminismos Plurais).

BAKHTIN, Mikhail. Marxismo e Filosofia da Linguagem. $12^{\text {a }}$ Ed. São Paulo: HUCITEC, 2006

BARATTA, Alessandro. O paradigma do gênero: da questão criminal à questão humana. In: CAMPOS, Carmen Hein (org). Criminologia e Feminismo. Porto Alegre: Editora Sulina, 1999

BOITEUX, Luciana. A nova lei antidrogas e o aumento da pena do delito de tráfico de entorpecentes. Boletim IBCCrim, São Paulo, ano 14, n. 167, p. 8-9, out. 2006.

BRASIL. DEPEN. Painel de monitoramento de casos suspeitos e confirmados de COVID-19 nos sistemas prisionais do mundo.

Disponível em:

https://app.powerbi.com/view?r=eyJrIjoiYThhMjk5YjgtZWQwYSooODlkLTg4 NDgtZTFhMTgzYmQ2MGVlIiwidCI6ImViMDkwNDIwLTQoNGMtNDNmNy05 MWYyLTRiOGRhNmJmZThlMSJg. Acesso em: 08/09/2020a

BRASIL. Atlas da Violência. IPEA, 202ob

BRASIL. Estatuto da Criança e do Adolescente: Lei 8069 de 13 de Julho de 1990. 7. ed.. Brasília, DF, 2012.

BRASIL. Levantamento Anual SINASE 2017. Brasília: Ministério da Mulher, da Família e dos Direitos Humanos, 2019.

BRASIL. Lei n. 11.343, de 23 de agosto de 20o6. Institui o Sistema Nacional de Políticas Públicas sobre Drogas - SISNAD; Brasília, 2006

CARNEIRO, Henrique S. As necessidades humanas e o proibicionismo das drogas no século XX. Outubro, São Paulo, v. 6, p. 115-128, 2002. 
D’ELIA FILHO, Orlando Zaccone. Indignos de vida: a forma jurídica da política de extermínio de inimigos na cidade do Rio de Janeiro. $1^{\mathrm{a}}$ ed. Rio de Janeiro: Revan, 2015.

DAVIS, Angela. A liberdade é uma luta constante. Organização Franck Rarat; Tradução Heci Regina Candiani. 1. Ed. São Paulo: Boitempo, 2018

DELMANTO, Júlio. Imperialismo e proibicionismo: raízes e interesses da proibição das drogas e da suposta guerra ao tráfico. 2010. NEIP: Núcleo de Estudos Interdisciplinares sobre Psicoativos. Disponível em: <http://www.neip.info/index.php/content/view/1459.html>. Acesso em: 15 mar. 2012.

DIWAN, Pietra. Raça pura: uma história da eugenia no Brasil e no mundo. São Paulo: Contexto, 2018

ESCOHOTADO, Antônio. História elementar das drogas. Lisboa: Antígona, 2004.

FALEIROS, Vicente de Paula. Infância e processo político no Brasil. In: RIZZINI, Irene; PILOTTI, Francisco (org.). A arte de governar crianças: a história das políticas sociais, das legislações e da assistência à infância no Brasil. 3. ed. São Paulo: Cortez, 2011.

FEFFERMAN, Marisa. Vidas arriscadas: o cotidiano dos jovens trabalhadores do tráfico. Petrópolis: Vozes, 2006.

FERRUGEM, Daniela. Guerra às Drogas: e a manutenção da hierarquia racial. Belo Horizonte: Letramento, 2019.

FLAUZINA, Ana Luiza Pinheiro. Corpo negro caído no chão: o sistema penal e o projeto genocida do Estado brasileiro. Rio de Janeiro: Contraponto, 2008.

GARLAND, David. A cultura do controle: crime e ordem social na sociedade contemporânea. Rio de Janeiro: Revan, 2014

GIORGI, Alessandro De. A miséria governada através do sistema penal. Rio de Janeiro: Revan; ICC, 2013

GÓES, Luciano. A “tradução" do paradigma etiológico de criminologia no Brasil: um diálogo entre Cesare Lombroso e Nina Rodrigues da perspectiva centro-margem. Dissertação de Mestrado em Direitos. UFSC, Florianópolis, SC, 2015.

GRAMSCI, Antonio. Americanismo e Fordismo. São Paulo: Hedra, 2008

JAMES, C. L. R. Os jacobinos negros: Toussant L'Ouverture e a revolução de São Domingos. São Paulo: Boitempo, 2010

KARAM, Maria Lucia. Não são as drogas que causam violência e criminalidade. Entrevistador: Fórum da Liberdade. 7 fev. 2012. Disponível em: $<$ http://forumdaliberdade.com.br/fl25/ blog/2012/nao-sao-as-drogas-quecausam-violencia-e-criminalidade-afirma-maria-lucia-karam/>. Acesso em: 20 fev. 2012. 
LIMA, Rita de Cássia Cavalcante. Uma história das drogas e do seu proibicionismo transnacional: relações Brasil-Estados Unidos e os organismos internacionais. 2009. 365 f. Tese (Doutorado em Serviço Social)Programa de Pós-Graduação em Serviço Social da Universidade Federal do Rio de Janeiro, Rio de Janeiro, 2009.

LOSURDO, Domênico. Contra-história do liberalismo. Aparecida - SP: Ideias e Letras, 2006.

MACHADO, Lia Osório. Estado, territorialidade, redes. Cidades gêmeas na zona de fronteira sul-americana. In: SILVEIRA, María Laura (Org.). Continente em chamas: globalização e território na América Latina. Rio de Janeiro: Civilização Brasileira, 2005.

MACHADO, Lia Osório. Limites e Fronteiras: da alta diplomacia aos circuitos da ilegalidade. Território, Rio de Janeiro, ano 5, n. 8, p. 7-23, jan./jun. 2000.

MALAGUTI BATISTA, Vera. O medo na cidade do Rio de Janeiro: dois tempos de uma história. Rio de Janeiro: Revan, 2014

MARX, Carl. O capital: crítica da economia política. V. 1 e 2. São Paulo: Nova Cultural, 1988. (Economistas)

MOURA, Clóvis. Sociologia do negro brasileiro. $2^{\mathrm{a}}$. ed. São Paulo: Perspectiva, 2019.

MUNANGA, Kabengele. Uma abordagem conceitual das Noções de Raça, Racismo, Identidade e Etnia. Palestra proferida no $3^{\circ}$ Seminário Nacional Relações Raciais e Educação-PENESB-RJ, 2003

NASCIMENTO, Abdias. O genocídio do Negro Brasileiro: processo de um racismo mascarado. $3^{\text {a }}$. Ed. São Paulo: Perspectivas, 2016

OLIVEIRA E SILVA, Maria Liduina. Entre proteção e punição: o controle sociopenal dos adolescentes. São Paulo: Editora UNIFESP, 2011.

PASSETTI, Edson. Das fumeries ao narcotráfico. São Paulo: EDUC, 1991

RIZZINI, Irene. Crianças e menores: do pátrio poder ao pátrio dever. Um histórico da legislação para infância no Brasil. In: RIZZINI, Irene; PILOTTI, Francisco (org.). A arte de governar crianças: a história das políticas sociais, das legislações e da assistência à infância no Brasil. 3. ed. São Paulo: Cortez, 2011.

ROCHA, Andréa Pires. Prisão Provisória de Jovens pelo crime de tráfico de drogas após a realização das Audiências de Custódia em Londrina/PR. Relatório Final de pesquisa Desenvolvida durante o Estágio de Pós Doutoramento no Programa de Pós Graduação em Serviço Social da ESSUFRJ, 2018

ROCHA, Andréa Pires. Trajetórias de adolescentes apreendidos como "mulas" do transporte de drogas na região da fronteira (Paraná) Brasil - Paraguai: exploração de força de trabalho e criminalização da pobreza. Tese Doutorado em Serviço Social - UNESP- Franca/SP, 2012.

RODRIGUES, Thiago M. S. Política e drogas nas Américas. São Paulo: EDUC; FAPESP, 2004. 
Revista Brasileira de História \& Ciências Sociais - RBHCS

Vol. $13 \mathrm{~N}^{\circ}$ 25, Edição Especial de 2021

SAAD, Luiza. Fumo de Negro. EDUFBA, 2019.

SALES, Mione Apolinário. (In)visibilidade perversa: adolescentes infratores como metáfora da violência. São Paulo: Cortez, 2007.

SANTOS, Milton. Espaço e sociedade. Rio de Janeiro: Vozes, 1979.

TRINDADE, José Damião de Lima. Os direitos humanos: para além do capital (Prefácio). In: BRITES, Cristina M.; FORTI, Valeria. (orgs) Direitos

Humanos e Serviço Social: polêmicas, debates e embates. Rio de Janeiro: Editora Lumen Juris, 2011

VALENZUELA, José Manuel (coord.). Juvenicidio: Ayotzinapa y las vidas precarias em America Latina y España. Barcelona: Ned Ediciones;

Guadalajara: ITESO; Tijuana: El Colegio de la Frontera Norte, 2015.

VALOIS, Luiz Carlos. O Direito Penal da Guerra às Drogas . 2 ed. $1^{\mathrm{a}}$.

Reimp. Belo Horizonte: D'placido, 2017

WACQUANT, Loïc . Punir os Pobres: a nova gestão da miséria nos Estados Unidos. Tradução de Sérgio Lamarão. Rio de Janeiro: Revan, 2003, $3^{\text {a }}$. edição, revista e ampliada, agosto de 2007. a $^{\mathrm{a}}$. reimpressão, março de 2013.

WACQUANT, Loïc. As prisões da miséria. Tradução de André Telles. Rio de Janeiro: Jorge Zahar, 2001.

WAISELFISZ, Julio Jacobo. Mapa da Violência 2016: homicídios por armas de fogo no Brasil. FLACSO-Brasil: 2017

WEBER, Max. A ética protestante e o "espírito" do capitalismo.

Tradução de José Marcos Mariani de Macedo ; revisão técnica António Flávio Pierucci. São Paulo : Companhia das Letras, 2004.

ZAFFARONI, Eugenio. O inimigo do Direito Penal. Rio de Janeiro: Revan, 2014

ZALUAR, Alba. Da revolta ao crime S/A. São Paulo: Moderna, 1996

Recebido em Agosto de 2020

Aprovado em Novembro de 2020

DOI: $\underline{\text { https://doi.org/10.14295/rbhcs.v13i25.119o8 }}$ 